\title{
PRÁTICAS DE GESTÃO PARA OTIMIZAÇÃO DA VIDA ÚTIL DE COMPUTADORES PESSOAIS: UM ESTUDO DE CASO NO CAMPUS DE SANTO ANDRÉ DA UNIVERSIDADE FEDERAL DO ABC
}

\author{
Bárbara Popovits Ribeiro \\ Mestre em Gestão Ambiental e Sustentabilidade pela Universidade Nove de Julho - UNINOVE \\ Professora da Universidade Federal do ABC - UFABC \\ barbara.ribeiro@ufabc.edu.br \\ Mauro Silva Ruiz \\ Doutorado em Geografia pela Southern Illinois University at Carbondale - SIUC \\ Professor do Mestrado Profissional em Gestão Ambiental e Sustentabilidade - GeAS/UNINOVE \\ maurosilvaruiz@uninove.br \\ Neusa Serra \\ Doutora em Engenharia de Produção pela Escola Politécnica - USP \\ Professora da Universidade Federal do ABC - UFABC \\ neusa.serra@ufabc.edu.br
}

\begin{abstract}
RESUMO
As instituições de ensino superior (IES), responsáveis pela formação de recursos humanos, precisam adotar em sua gestão práticas sustentáveis para atender à legislação em vigor e servir de exemplo a outras organizações e à sociedade em geral. Como a UFABC é uma instituição nova e ainda está amadurecendo os seus processos internos de gestão, o objetivo deste estudo é propor práticas de gestão sustentável direcionadas à otimização da vida útil dos computadores obsoletos tendo como referência o Princípio dos 3 Rs - Reduzir, Reutilizar e Reciclar. A questão de pesquisa, alinhada a este objetivo é a seguinte: como as práticas de gestão dos computadores pessoais do campus da UFABC de Santo André - SP precisarão evoluir para que uma política destinada ao prolongamento da vida útil desses equipamentos possa ser proposta? A metodologia consistiu em levantamento bibliográfico e documental, observação direta e entrevistas. Os resultados indicaram que a Universidade ainda não tem procedimentos sistematizados para a gestão visando à otimização da vida útil dos computadores obsoletos. No entanto, além de já ter práticas para o gerenciamento dos computadores novos, informalmente também já vem reaproveitando peças e componentes de alguns equipamentos condenados ao descarte. Espera-se que os resultados deste estudo possam auxiliar a UFABC a reavaliar as suas práticas atuais e subsidiar a implantação de uma política institucional de gestão de TI enfatizando a ampliação da vida útil dos computadores pessoais.
\end{abstract}

Palavras-chave: Computadores pessoais; Gestão ambiental; Gestão de resíduos; Instituições de ensino superior públicas.

\section{MANAGEMENT PRACTICES FOR OPTIMIZATION OF LIFE OF PERSONAL COMPUTERS: A CASE STUDY IN THE CAMPUS OF SANTO ANDRÉ FEDERAL UNIVERSITY IN ABC \\ ABSTRACT}

Higher education institutions (HEIs), responsible for the training of human resources, need to adopt sustainable practices in their management ways in order to meet the legislation and serve as example to other organizations and society in general. As the Universidade Federal do ABC (UFABC) is a new institution and is still maturing their internal management processes, the aim of this study is to propose sustainable management practices for optimizing the computers life of obsolete equipment. For reference we adopted the principles of the $3 \mathrm{Rs}$ - Reduce, Reuse and Recycle. The research question in line is: how management practices of personal computers of the campus St. André's of UFABC - SP which need to evolve a policy aimed at extending the life of these devices equipment can be proposed? The methodology consisted of bibliographical and documentary survey, direct observation and interviews. The results indicate that the University has no systematic procedures for the management for optimizing the computer life of obsolete equipment. However, the University already has practices for managing new computers, and informally also reuses parts and components from some equipment convicted disposal. We expected that the results of this study might help UFABC to re-evaluate their current practices and support the implementation of an institutional policy of IT management emphasizing the extension of the useful life of PCs.

Keywords: Environmental management; Personal computers; Public higher education institutions; Waste management. 


\section{INTRODUÇÃO}

A utilização de equipamentos eletroeletrônicos (EEEs) é indispensável na sociedade do conhecimento impulsionando fortemente a oferta desses produtos e o acúmulo de resíduos deles derivados. Em resposta à demanda crescente, a dinâmica tecnológica da indústria eletroeletrônica tem motivado a obsolescência programada, ou seja, a substituição desses equipamentos em períodos de tempo cada vez mais curtos reduzindo suas vidas úteis. Essa obsolescência é facilitada pelos apelos de marketing, que incentivam a compra de modelos cada vez mais modernos e sofisticados.

Visando otimizar a vida útil dos EEEs, instituições de ensino superior (IES) estão adotando políticas de gestão de tecnologia de informação (TI), em especial de computadores pessoais.

Um pressuposto deste estudo é que as universidades públicas, por desempenharem um papel estratégico na disseminação de novos padrões de produção e consumo, têm um papel exemplar na redução de impactos socioambientais negativos gerados por suas atividades (Brasil, 2014). Outro pressuposto é que a crescente produção e consumo de equipamentos de TI na sociedade atual não se mostram alinhados com os três pilares da sustentabilidade.

Há experiências de gestão de resíduos de equipamentos eletroeletrônicos (REEEs) na Universidade Estadual Paulista - Unesp e em várias Universidades Federais como as de São Carlos, de Santa Catarina, de Viçosa, de Uberlândia, do Ceará, da Paraíba, do Paraná e do Rio Grande do Sul (Natume et al., 2011; Menezes, 2014).

Segundo Veit (2010), o Brasil produz anualmente cerca de 300.000 toneladas de REEEs sendo uma parte considerável deste montante constituída por computadores obsoletos, quebrados ou em desuso. Em função da redução da vida útil (3 anos em média), rápido descarte, e existência de substâncias nocivas ao meio ambiente e à saúde humana em suas composições, ações visando à redução, reutilização e reciclagem desses resíduos são cada vez mais necessárias.

Vários autores têm se dedicado ao assunto com abordagens variadas: reuso de computadores (Novaes \& Zanta, 2011), reciclagem (Ravi, 2012), avaliação do ciclo de vida do computador (Esposito \& Mastroianni, 2002; Choi et al., 2006; Teehan \& Kandlikar, 2012), cadeia de suprimentos de computadores (Kahhat \& Williams, 2009; Wu, 2012; Rahman \& Subramanian, 2012), obsolescência programada (Carvalho, 2013, Nordin et al., 2015), logística reversa (Santos \& Souza, 2009; Xavier et al., 2010) e gestão de resíduos de EEE (Garcia et al., 2012; Schons, 2012; Bueno et al., 2013).

No Brasil uma maior atenção passou a ser dedicada a esses resíduos após a sansão da Política Nacional de Resíduos Sólidos - PNRS (Brasil, 2010). No entanto, mesmo com a responsabilização dos fabricantes, importadores, distribuidores e comerciantes, consumidores e os titulares dos serviços públicos de limpeza urbana pelos resíduos sólidos gerados, as tentativas de acordos setoriais para por em prática a gestão compartilhada, preconizada pela lei, ainda não lograram êxito. Neste sentido, a situação descrita por Bizzo (2007), de que a articulação voluntária entre os elos da cadeia produtiva para a recuperação ou reciclagem REEEs era muito pequena, não parece ter evoluído desde então.

A análise das práticas atuais de gestão de computadores da UFABC reveste-se de importância pelo fato da Universidade estar montando seu parque de tecnologia da informação (TI) e motivada a definir uma política de gestão para os seus equipamentos.

Nesta pesquisa optou-se por analisar as práticas de gestão dos computadores pessoais do campus da UFABC de Santo André - SP visando propor uma política destinada ao prolongamento da vida útil desses equipamentos tendo como referência o Princípio dos 3Rs: Reduzir, Reutilizar, Reciclar.

A questão de pesquisa, alinhada a este objetivo, é a seguinte: como as práticas de gestão dos computadores pessoais do campus da UFABC de Santo André - SP precisarão evoluir para que uma política destinada ao prolongamento da vida útil desses equipamentos possa ser proposta? 


\section{REFERENCIAL TEÓRICO}

O referencial teórico inicia-se apresentando um breve descritivo das inovações tecnológicas dos computadores pessoais a partir da visão de autores selecionados. Em seguida, apresenta-se a gestão sustentável de resíduos em organizações, as práticas de gestão sustentável de resíduos dos computadores pessoais em instituições de ensino superior e a Agenda ambiental na administração pública - A3P.

\subsection{Inovações tecnológicas dos computadores pessoais}

Do ponto de vista técnico, os EEEs são aqueles equipamentos cujo adequado funcionamento depende de correntes elétricas ou campos eletromagnéticos, bem como os utilizados para geração, transferência e medição dessas correntes e campos, concebidos para utilização com uma tensão nominal não superior a $1000 \mathrm{~V}$ para corrente alternada e $1500 \mathrm{~V}$ para corrente contínua (Comunidade Europeia, 2002).

Após o final de suas vidas úteis os EEEs são classificados como resíduos sólidos de equipamentos eletroeletrônicos - os REEEs. Esses resíduos incluem todos os componentes, subconjuntos e materiais consumíveis que fazem parte do produto no momento em que este é descartado (Comunidade Europeia, 2002).

A Norma 10.004 da Associação Brasileira de Normas Técnicas (ABNT) apresenta um fluxograma com informações sobre a periculosidade de resíduos que permite situar os resíduos de computadores na Classe I, como perigosos. Isso se deve ao fato deles terem em seus componentes elementos tóxicos que podem contaminar as águas, o ar e o solo (Associação Brasileira de Normas Técnicas, 2004).

De acordo com Manthou et al. (2013) o uso e venda de EEEs tem aumentado exponencialmente durante as duas últimas décadas, particularmente devido ao desenvolvimento de novas tecnologias e das telecomunicações. E o crescimento do mercado, as inovações e os hábitos de consumo tecnológicos resultam em substituição rápida e contínua dos EEEs, consequentemente levando os a ciclos de vida mais curtos, e aumentando a geração de REEEs, sendo sua disposição em aterros não só prejudicial ao meio ambiente, mas também, economia pois metais preciosos e recursos naturais raros são desperdiçados.

Segundo Novaes \& Zanta (2011) o consumo elevado dos computadores contribui para o descarte precoce, em estágio da vida útil em que ainda estão completamente funcionais. A simples substituição de peças defeituosas propiciaria a continuidade de uso nesses casos, porém, o que se observa, na prática, é que as constantes trocas de softwares acabam impondo a necessidade de mais recursos de hardware, exigindo reposição de peças e equipamentos com geração resíduos.

Dados divulgados pela Fundação Getúlio Vargas (2013) sobre a utilização da TI indicam que o número de computadores em uso no Brasil atingiu o montante de 118 milhões de unidades em maio de 2013. Esse número era de 1 milhão em 1988 e 10 milhões em 2000. As estimativas indicam que 200 milhões de aparelhos estarão em uso no país entre 2016 e 2018.

Estudos de Lima Jr. \& Oiko (2009 citado por Novaes \& Zanta, 2011) mostraram variações significativas nas vidas úteis de computadores adquiridos nas últimas décadas pela Universidade Estadual de Maringá (UEM). Os adquiridos na década de 1980 tiveram um ciclo de vida de 18 anos enquanto os adquiridos na década de 2000 tiveram uma vida útil de apenas 5 anos. Ou seja, a intensa dinâmica tecnológica e a obsolescência programada no segmento de computadores pessoais reduziu em 13 anos o ciclo de vida desses equipamentos na UEM em apenas duas décadas.

Em relação às substâncias tóxicas presentes nos computadores pessoais, Tsydenova \& Bengtsson (2011) e Nordin et al. (2015), alertam que atenção especial deve ser dada aos resíduos de monitores devido à presença de chumbo no vidro do cone, de bário no canhão de elétrons e de cádmio no pó fosforescente. As placas de circuito impresso também merecem atenção devido à presença das seguintes substâncias perigosas: chumbo e estanho na solda, cádmio e berílio nos contatos, mercúrio nos conectores, e componentes bromados na resina polimérica dos retardantes de

Revista de Gestão Social e Ambiental - RGSA, São Paulo, v. 9, n. 3, p. 80-96, set./dez., 2015. 
chama. O chumbo é destacado como um dos mais perigosos devido ao seu efeito cumulativo no meio ambiente e por causar sérios danos ao sistema nervoso dos seres humanos. Na lista de periculosidade, o mercúrio também se destaca, pois pode acarretar danos ao cérebro, rins e a fetos em formação.

\subsection{Gestão sustentável de resíduos em organizações incluindo as instituições de ensino superior}

O termo gestão sustentável vem ganhando maior adesão das organizações à medida que a sustentabilidade vem sendo incorporada em suas práticas de gestão. O desenvolvimento sustentável ganhou novas dimensões no relatório Nosso Futuro Comum de 1987 e passou a ter a conotação do desenvolvimento que atende às necessidades do presente sem comprometer a possibilidade das gerações futuras atenderem também as suas (Comissão Mundial sobre Meio Ambiente e Desenvolvimento, 1987).

Em 2002 a Cúpula Mundial para o Desenvolvimento Sustentável, realizada em Johanesburgo, enfatizou que o desenvolvimento sustentável é construído sobre três pilares interdependentes: o desenvolvimento econômico, o desenvolvimento social e a proteção ambiental, endossando o que já havia sido preconizado por Elkington (2001) nesse sentido. Mais recentemente, as preocupações sociais e ambientais, que antes eram vistas de forma dissociada da dimensão econômica, passaram a ser discutidas conjuntamente nas organizações públicas e privadas, que aderiram às práticas sustentáveis como uma vantagem competitiva. No contexto dessas práticas, essas organizações, incluindo as IES, vêm desenvolvendo sistemas de gestão ambiental que abrangem a gestão dos REEEs.

Segundo a Norma ISO 14001 a gestão ambiental de uma organização pressupõe que ela desenvolva e implemente uma política ambiental, explicitando suas intenções e princípios gerais em relação ao seu desempenho ambiental. Esta gestão contempla os aspectos e impactos ambientais das atividades, serviços ou produtos da organização que interagem com o meio ambiente (Associação Brasileira de Normas Técnicas, 2004).

De acordo com Aligleri et al. (2009), a responsabilidade socioambiental deve ser vista como uma extensão da gestão ambiental na qual a organização explicita suas preocupações com o impacto social de sua atuação, decisões e rotinas gerenciais, políticas de compras, consumo de recursos não renováveis, segurança e comprometimento com a sociedade.

Tauchen \& Brandli (2006) afirmam que as IES começaram a introduzir práticas de gestão ambiental a partir de 1960. Nos anos de 1980 tiveram destaque as políticas de gestão de resíduos e de eficiência energética e, nos anos de 1990, as políticas ambientais de âmbito mais global. Dois importantes exemplos da década de 1990 são, respectivamente, o do campus Ecology da University of Wisconsin at Madison e o do Brown is Green da University of Brown, ambos nos EUA. No entanto, o compromisso das IES com o desenvolvimento sustentável se manifesta mais claramente nas declarações de Talloirdes em 1990, de Halifax em 1991, de Swansea em 1993, de Kyoto em 1993, na Carta Copernicus em 1994 e, por fim, na Declaração de Haga em 2000.

Mais recentemente, reconhecendo a necessidade urgente de integrar questões do desenvolvimento sustentável aos princípios da educação, a UNESCO declarou 2005 - 2014 como a década da Educação para o Desenvolvimento (Zhang et al., 2011).

Velazquez et al. (2006, citado por Zhang et al. 2011), consideram sustentável a IES em que todos os seus integrantes estejam comprometidos com a alocação de recursos para a minimização dos impactos negativos de suas atividades no meio ambiente, na saúde coletiva, no meio social e na área econômica, via o cumprimento de suas funções de ensino, pesquisa, disseminação de conhecimento e parceria. Segundo esses autores, uma IES sustentável tem plena consciência do seu papel e responsabilidade na formação de cidadãos críticos que ajudarão na transição da sociedade para a assimilação de estilos de vida sustentáveis. 
Para Zhang et al. (2011) são cinco os fatores determinantes de sucesso de uma IES no trato de questões ambientais: (i) necessidade de entendimento do funcionamento e do processo de tomadas de decisão nessas instituições; (ii) existência de compromisso, apoio e disponibilidade de recursos para o enfrentamento das questões e desafios ambientais; (iii) existência de mecanismos para coordenação, comunicação e divulgação da temática ambiental; e (iv) disponibilidade de infraestrutura e possibilidades de formalização de parceiras com empresas para execução de atividades ambientalmente sustentáveis.

A partir de um estudo sobre a efetividade da implementação de gestão de resíduos em IES envolvendo 84 universidades do Reino Unido, Zhang et al. (2011) concluíram que para garanti-la é necessário a nomeação de um indivíduo responsável por esse processo. Concluíram também que o envolvimento de um pequeno grupo de pessoas comprometido com iniciativas ambientais em cada departamento pode tornar a comunicação das práticas sustentáveis internas de toda a organização mais eficientes. Esses autores destacaram ainda que para as IES obterem resultados sustentáveis positivos na gestão de seus resíduos, suas práticas devem se basear nas seguintes ações: (i) redução da geração; (ii) adoção de práticas de reutilização e reciclagem; e (iii) utilização de metas quantitativas para cada fase. Esses autores concluem o estudo enfatizando que os principais problemas enfrentados na gestão de resíduos em IES no Reino Unido relacionam-se à falta de coordenação interna da atividade, à burocracia institucional e à falta de planejamento.

Segundo Kunal \& Anwesha (2013) na Índia não só instituições de ensino mas também a indústria de TI (Tecnologia da Informação), os escritórios governamentais, os estabelecimentos públicos e privados destinam a gestão dos REEEs aos catadores de lixo, sucateiros e recicladores que coletam e transportam esses materiais e, realizam operações de segregação, desmontagem e venda dos materiais, além do recondicionamento para mercados de segunda mão e reciclagem.

Nos últimos anos, vários autores em nível mundial, vêm estudando o tema REEEs também denominados informalmente de "lixo eletrônico" ( $e$-waste em Inglês). Destacando o reuso de computadores (Novaes \& Zanta, 2011), reciclagem (Ravi, 2012), avaliação do ciclo de vida do computador (Esposito \& Mastroianni, 2002; Choi et al., 2006; Teehan \& Kandlikar, 2012; Wong et al., 2013), remanufatura (Gao et al., 2012), cadeia de suprimentos de computadores (Kahhat \& Williams, 2009; Wu, 2012; Rahman \& Subramanian, 2012), obsolescência programada (Carvalho, 2013), logística reversa (Santos \& Souza, 2009; Xavier et al., 2010) e gestão de resíduos de EEE (Garcia et al., 2012; Schons, 2012; Bueno et al., 2013).

De acordo com Manthou et al. (2013) na literatura pode ser encontrado sobre o tema sistemas de gestão de REEEs estudos que tratam da sua eficiência, adequação, problemas e desafios, bem como, sobre legislação, análise de políticas públicas, desenvolvimento de sistemas de gestão dos REEEs, custos da gestão, processos que melhorem as características dos EEEs para facilitar a desmontagem e reaproveitamento, e também, fluxos de gestão para os REEEs ao final de suas vidas úteis, como por exemplo o que é mostrado na figura abaixo:

Figura 1. Fluxo de opções para EEE no final da vida útil

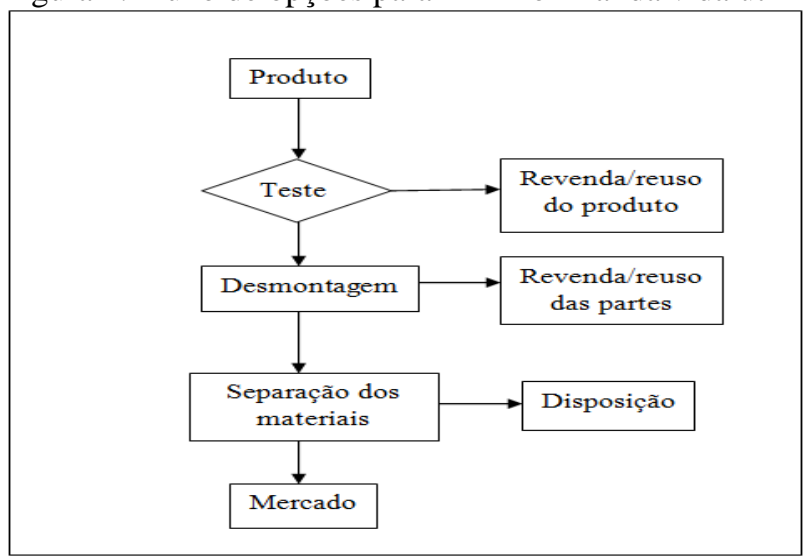

Fonte: Adaptado de Manthou et al. (2013) 
Em síntese, a partir dos estudos analisados, pode-se dizer que as IES têm um papel fundamental a desempenhar na difusão de conhecimentos, valores e práticas ambientais sustentáveis para toda a sociedade. Neste contexto, a implementação da gestão dos resíduos sólidos propicia, além de benefícios ambientais, aprendizados relevantes que podem ser disseminados para outras instituições similares do país e do exterior.

\subsection{Práticas de gestão sustentável de resíduos de computadores pessoais em instituições de ensino superior}

A designação práticas de gestão sustentável de resíduos de computadores compreende um conjunto de ações fundamentadas no Princípio dos 3Rs - Reduzir, Reutilizar, Reciclar - a ser conduzido por equipes internas das IES visando a otimização da vida útil desses equipamentos.

O Princípio dos 3Rs preconiza a redução de matérias-primas utilizadas na fabricação de novos produtos com vistas a poupar recursos naturais, água e energia, além de evitar que os resíduos pós uso desses produtos sejam encaminhados para aterros ou incineradores. Esse Princípio se alinha aos princípios da sustentabilidade, em especial aos da prevenção, precaução, cooperação e responsabilização. Experiências de implementação dos 3Rs em IES já ocorreram em vários países da Europa, EUA, China, Japão e em algumas nações em desenvolvimento (Samiha, 2013; Nordin et al., 2015).

Peters (2009) menciona que as causas mais comuns que levam as pessoas a se desfazerem dos computadores relacionam-se à lentidão de funcionamento devido a spyware, vírus, arquivos temporários, arquivos fragmentados e discos rígidos cheios. Esse autor recomenda que antes de reciclar um computador lento ou reformatar o seu disco rígido, o proprietário ou o usuário deve se informar sobre os procedimentos existentes para a melhoria do seu desempenho como, por exemplo, executar ferramentas de manutenção do sistema operacional. Já a sua venda, doação ou recondicionamento deve ser feita somente quando todas as possibilidades de extensão de sua vida útil forem esgotadas. Esse autor lembra também que sempre é bom verificar se o fabricante oferece programas de retorno do computador ao final de sua vida útil.

Segundo Babbitt et al. (2011), foram identificadas quatro práticas comuns de gestão de computadores em universidades: (i) compra de equipamentos com certificado "verde", fabricados com materiais recicláveis e fáceis de desmontar e reutilizar; (ii) implementação de renovação de tecnologia ou aluguel com o propósito de retornar para a empresa que a alugou para que ela tenha a responsabilidade pelo destino final do equipamento; (iii) contratação de um reciclador e/ou leilão público de equipamentos somente quando o equipamento tem potencial de reuso e (iv) adoção de políticas que priorizem o uso mais prolongado dos equipamentos e o apoio técnico da TI para efetuar manutenções de rotina e atualizações, diminuindo a quantidade dos REEEs.

As IES também podem se basear na Norma ISO 20.000 como um padrão de referência de melhores práticas para serviços de TI. Essa norma contém instruções que podem guiar a empresa na gestão da sua TI com qualidade, compatível com o ITIL (Information Technology Infrastructure Library), que trata do gerenciamento de serviços de TI. Na Norma ISO 20.000, há os processos de serviço, capacidade de gerenciamento, serviço de continuidade e gerenciamento de disponibilidade, gerenciamento de nível de serviço, relatórios de serviço, gestão de segurança da informação, orçamento e contabilidade para serviços de TI, processos de resolução, gerenciamento de incidentes, gerenciamento de problemas, gerenciamento de configuração, gestão de mudança, gestão de relacionamento de negócios, gestão de fornecedores (Norma ISO/IEC 20.000, International Organization for Standardization, 2005). Essas diretrizes são importantes, pois suas observações podem ajudar as IES a gerirem seus recursos e serviços de TI com qualidade.

Alguns exemplos de práticas de gestão de resíduos em IES são oferecidos pelo Instituto de Educação Ciência e Tecnologia do Amazonas - IFAM, campus Manaus, pela Unigranrio, campus Magé, pela Universidade Federal do Rio Grande do Sul -UFRGS, pelo Griffith College da Irlanda, pelas Universidades do Klang Valley, pela Universidade de Sydney, Universidade de Macquarie,

Revista de Gestão Social e Ambiental - RGSA, São Paulo, v. 9, n. 3, p. 80-96, set./dez., 2015. 
Universidade de Griffith da Austrália, pela Universidade de Illions, Universidade do Kansas, Universidade de Indiana, Universidade de Auburn e pela Universidade de Columbia nos Estados Unidos (EUA).

As práticas do IFAM se resumem a práticas de recolhimento e doação para outras instituições de equipamentos eletrônicos em desuso, incluindo microcomputadores, teclados, mouse, nobreak, caixas de som e CPUs (Silva, 2010).

A Unigranrio de Magé implantou em seu pátio um ecoponto para a coleta de materiais eletrônicos, microcomputadores e celulares. A empresa coletora é a Perterson Reciclagem que envia esses REEEs para unidades de reaproveitamento e remanufatura de computadores e celulares (Santos et al., 2014).

Na UFRGS os computadores obsoletos são doados para programas governamentais como o "Programa Computadores para Inclusão" que possuem centros de recondicionamento de computadores chamados de CRC, ou são leiloados, porém sem saber o destino final desses REEEs. A própria universidade alega que o melhor caminho seria aproveitar internamente os computadores antes de se desfazerem, e justificam que isso não ocorre por limitação de pessoal que destina equipamentos bons para o desfazimento (Neutzling et al., 2014).

Estudo realizado em 7 Universidades do Klang Valley relatou que algumas Universidades armazenam os REEEs por um longo período antes de serem eliminados, e também fazem doações em escolas e grupos vulneráveis, melhorando a imagem da instituição em termos de responsabilidade social, ou vendem os REEEs para a reciclagem ou comerciantes de eletrônicos de segunda mão, o que gera um dinheiro de retorno para as universidades, assim como, tira da instituição a responsabilidade pela gestão daqueles resíduos. Há também o serviço de recolha de grandes empresas como Dell, Hewlett Packard e Samsung que destinam para a manufatura os resíduos eletrônicos. No entanto, a maioria das instituições efetuam uma prática preocupante que consiste em jogar no lixo partes de computadores, monitores e impressoras (Nordin et al., 2015).

Davis \& Wolski (2009) descrevem um processo de compra de 5.000 computadores no Griffith College que considerou o menor consumo de energia como critério ambiental determinante. Destacam que a referida instituição não tem uma política de gestão dos REEEs, mas tem adotado práticas como vendas em leilões públicos, repasses para uso por alunos e vendas para recicladoras de metal.

Em levantamento realizado por Nordin et al. (2015), na Universidade de Sydney os REEEs são recolhidos e desmontados, então os materiais são reutilizados ou encaminhados para a reciclagem. A Universidade de Macquarie colocou em prática uma política de resíduos focada no meio ambiente e na sustentabilidade para eliminação dos equipamentos não desejados e ou obsoletos, os REEEs são recolhidos e armazenados até serem recolhidos por uma empresa de reciclagem. Com essa política de resíduos essa universidade tem desviado grande quantidade de resíduos que teria sido destinados para aterros sanitários. Já a Universidade de Griffith embarcou em iniciativas de gestão de resíduos, onde uma equipe de universitários desmontam os REEEs em conformidade com a política de alienação de ativos da universidade e encaixotam para a destinar para a reciclagem. Essa caixa tem certificação ISO 14001 e tem uma política de envio zero para aterros.

$\mathrm{Na}$ Universidade de Illinois há pesquisas em design na área de concepção de produtos relacionados aos EEE sem descuidar da responsabilidade para com ambiente, para reduzir a geração de resíduos enquanto considera o ciclo de vida. Já na Universidade do Kansas há departamentos que removem completamente os dados privados e confidenciais de computador e dispositivos móveis de armazenamento, incluindo controladores externos, monitores, impressoras e, fitas antes de despejálos com segurança sem prejudicar o meio ambiente, removendo quaisquer materiais nocivos. Na Universidade de Indiana é feita a coleta e envio dos REEEs para serem reciclados de forma adequada. A Universidade de Auburn se orgulha em ser um campus sustentável e reconhece que a eliminação de resíduos num aterro poderá lixiviar substâncias nocivas como mercúrio, arsênico e chumbo nas águas subterrâneas ou vias aéreas. Já a Universidade de Columbia tem um programa de 
recolha de resíduos que recolhe os REEEs por um preço barato nos campus e depois leva para uma área central onde uma empresa de reciclagem recolhe os materiais (Nordin et al., 2015).

\subsection{Agenda ambiental na administração pública - A3P}

A A3P é um programa de gestão socioambiental do governo federal que surgiu em 1999 e que em 2002 ganhou o prêmio da UNESCO denominado "O melhor dos exemplos" na categoria Meio Ambiente. Em 2007 a administração da A3P passou para o Departamento de Cidadania e Responsabilidade Socioambiental (DCRS) pertencente à Secretaria de Articulação Institucional e Cidadania Ambiental (SAIC). Atualmente a A3P é regulada pelas Portarias no 217 de 30 de julho de 2008 que, institui o Comitê de Implementação da A3P no Ministério do Meio Ambiente e, pela Portaria $n^{\circ} 61$ de 15 de maio de 2008, que estabelece práticas de sustentabilidade ambiental nas compras públicas (Ministério do Meio Ambiente, 2014).

Alguns procedimentos da A3P são parecidos com os da Norma ISO 14.001, com destaque para os 3Rs (Reduzir, Reciclar e Reutilizar) que se aplicam aos resíduos da administração pública federal. A A3P, no entanto, não estabelece como requisitos os levantamentos dos aspectos e impactos ambientais ao longo do ciclo de vida da produção ou dos serviços como sugerido, porém não exigido, nos planos de emergência que compõem a Norma ISO 14.001 (Barata et al., 2007).

Uma das razões para criação da A3P é o volume de compras governamentais que movimenta de 10 a 15\% do Produto Interno Bruto brasileiro. A sua adoção procura reduzir os impactos socioambientais negativos originados pela administração pública e fortalecer o papel indutor de novas práticas do governo (Ministério do Meio Ambiente, 2014). Como a utilização e o descarte anual de computadores pessoais na administração pública é considerável, a abrangência desse programa que contempla a gestão desses equipamentos ao longo de suas vidas úteis.

\section{METODOLOGIA}

A pesquisa foi realizada no campus da UFABC de Santo André - SP tendo como objetos de estudo os setores Coordenação Geral de Suprimentos e Aquisições (CGSA) e o Núcleo de Tecnologia da Informação (NTI). Na CGSA, apenas a Divisão de Patrimônio foi contemplada e no NTI as atenções se concentraram principalmente nas áreas de Suporte Técnico e Almoxarifado, e dentro do Suporte Técnico foi entrevistado um representante da área que participa das decisões do setor com a alta direção da Universidade.

$\mathrm{O}$ estudo em questão é de natureza qualitativa fundamentado em estudo de caso na perspectiva de Yin (2005). Segundo Martins e Theóphilo (2009), a preocupação central da pesquisa qualitativa situa-se nas descrições, compreensões e interpretações de fatos ao invés de medições.

Como não foi identificado nenhum estudo anterior sobre gerenciamento de computadores na UFABC, a presente pesquisa também tem caráter exploratório. Em vista disso, o estudo de caso em questão pode ser classificado como causal / exploratório (Yin, 2005; Creswell, 2007), o qual possibilita levantar e sistematizar os principais elementos relacionados ao assunto em foco e a partir dele fazer algumas generalizações.

A condução do estudo de caso baseou-se em revisão bibliográfica, levantamento documental, observações diretas e entrevistas.

A revisão bibliográfica se concentrou em artigos de revistas indexadas que abordam a dinâmica tecnológica e a rápida obsolescência dos EEEs enfatizando computadores pessoais livros, dissertações de mestrado e sites especializados no assunto também foram consultados.

$\mathrm{Na}$ revisão documental foram analisadas a legislação pertinente ao assunto e diversos documentos institucionais obtidos no próprio site da UFABC e/ou via colaboradores. Esses documentos compreendem atas de reuniões, relatórios de gestão, editais, instruções de trabalho, relatórios de metas e ações para aquisição e gerenciamento interno dos computadores pessoais. 
As observações diretas foram feitas em visitas aos locais de armazenamento dos computadores obsoletos no mês de junho de 2014. Para o registro de informações utilizou-se um checklist previamente elaborado e uma câmera fotográfica.

Em 2013 e em fevereiro e abril de 2014 foram realizadas 4 entrevistas informais, com o propósito de ajustar o escopo do estudo e melhor definir as questões que comporiam o roteiro final das entrevistas. Este roteiro, composto por 16 questões abertas, foi aplicado no período de maio e novembro de 2014.

A amostra de colaboradores para a entrevista, composta por nove pessoas oriundas de setores diferentes, foi do tipo não probabilística intencional. As entrevistas tiveram uma duração média de uma hora e foram gravadas visando um melhor aproveitamento das informações.

As questões da entrevista procuraram identificar se na Universidade haviam sistemas de gestão, ambiental ou de resíduos de computadores pessoais, incluindo fluxos e processos caso houvesse, qual era a estrutura organizacional com funções e responsabilidades atribuídas aos envolvidos na gestão dos computadores pessoais, também questionou-se se era adotado princípios dos 3R's (reduzir, reutilizar e reciclar) ou práticas para prolongar a vida útil dos computadores, questionou-se sobre os recursos disponíveis, tanto físicos, quanto humanos e financeiros, assim como estimativas mensais ou anuais de compras de computadores, custos, demanda, manutenção e geração de resíduos e, também perguntou-se se haviam locais para acondicionar os computadores obsoletos, qual era a periodicidade do manejo desses resíduos e, se era feito o acompanhamento dos destinos finais dos resíduos dos computadores. Também foi questionado quais os requisitos legais foram seguidos pela Universidade, quais fatores dificultam uma gestão dos computadores para prolongar a sua vida útil bem como os desafios para a Universidade.

As informações obtidas foram transcritas por um profissional especializado e, posteriormente, categorizadas por tópicos, obedecendo à sequência das perguntas do roteiro. Este procedimento de categorização, além de propiciar a identificação de palavras e expressões-chave, facilitou o confronto e a análise das informações obtidas. Esses dados foram complementados com observações diretas na Universidade e possibilitaram a triangulação dos dados com as entrevistas, principalmente sobre as características e condições de armazenamento dos EEE e REEE.

Para a interpretação dos resultados procedeu-se a uma sistematização dessas informações justapondo, lado a lado, todas as respostas dos nove entrevistados, levando em consideração as seguintes categorias: armazenamento dos computadores obsoletos; organização da atividade de desfazimento; planejamento para manutenção dos computadores em uso; e aquisições de novos computadores.

\section{RESULTADOS}

Pelas informações obtidas pode-se constatar que não há um sistema de gestão ambiental ou de resíduos de computadores pessoais estruturado na UFABC. As atuais práticas do setor responsável, o Núcleo de Tecnologia da Informação (NTI), se resumem em comprar, distribuir e armazenar computadores novos e obsoletos. Com o intuito de atender às legislações pertinentes aos bens públicos de TI, observa-se que a Universidade ainda está dando os seus primeiros passos na organização de um processo interno de desfazimento dos computadores obsoletos.

Com o intuito de facilitar a apresentação dos resultados e dar uma ideia das limitações e perspectivas das práticas atuais de gestão de computadores da Universidade, esse item foi estruturado em quatro subitens, quais sejam: armazenamento dos computadores obsoletos; organização da atividade de desfazimento; planejamento para manutenção dos computadores em uso; e aquisições de novos computadores.

\subsection{Armazenamento dos computadores obsoletos}

Atualmente as orientações de armazenamento de computadores novos e obsoletos são dadas pelo Coordenador Geral do NTI, que obedece aos seguintes procedimentos: (i) diagnóstico do 
equipamento pela área do Suporte Técnico mediante chamada do usuário; (ii) análise do problema caso seja no hardware, procede-se à substituição por um novo; e (iii) classificação do equipamento defeituoso como obsoleto e envio para o "lixão" da Universidade (denominação informal dada pelos colaboradores para o local onde são armazenados os computadores descartados).

Uma crítica dos entrevistados a este processo, é que os computadores que eventualmente poderiam ser recondicionados estão sendo "condenados" indevidamente e substituídos por novos sem uma avaliação pormenorizada.

Constatou-se que existem na Universidade em torno de 4.700 computadores de diversos modelos e marcas (HP, Dell, Itautec e Positivo) dos quais 3.800 estão em uso. Constatou-se também que para os computadores em desuso, as ações de manutenção são esporádicas se concentrando em reaproveitando peças de em outros equipamentos do mesmo modelo. Via edital interno, 56 computadores descartados no "lixão" da Universidade já foram recondicionados e redistribuídos internamente na Universidade. Isso mostra que mesmo sem o respaldo de uma política de gestão de EEEs, iniciativas pontuais de reaproveitamento de peças e componentes de computadores vêm sendo adotadas.

\subsection{Organização da atividade de desfazimento}

Constatou-se que há previsão de criação de um grupo de trabalho para diagnosticar e classificar os computadores obsoletos de acordo com o Decreto 99.658/90 (Brasil, 1990), que regulamenta, no âmbito da Administração Pública Federal, o reaproveitamento, movimentação, alienação e outras formas de desfazimento desses equipamentos. Atualmente dos cerca de 500 computadores existentes no "lixão" da Universidade, um lote de 200 de um modelo específico da Itautec aguarda diagnóstico visando o desfazimento.

Prevê-se que a área de Suporte Técnico do NTI tenha uma oficina em futuro próximo para efetuar as manutenções nos computadores. Esta área também se responsabilizará pelas futuras triagens dos resíduos de computadores que serão destinadas ao Almoxarifado também vinculado ao NTI. Esse upgrade na infraestrutura propiciará a criação de uma rotina de atividades para o processo de desfazimento.

A ideia é iniciar um novo processo de desfazimento sempre que um lote 100 computadores obsoletos for formado. Considerando que os recursos auferidos com os leilões dos equipamentos obsoletos e suas partes retornam aos cofres da União, uma gestão mais eficiente dos computadores e acessórios pelo NTI é importante para garantir a otimização de suas vidas úteis dentro da Universidade.

\subsection{Planejamento para manutenção dos computadores em uso}

A análise de documentação interna revelou que a Universidade possui alguns procedimentos estabelecidos para a gestão de computadores novos e em uso. Referem-se basicamente a manuais e tutoriais para uso do pessoal do Suporte no RT (Request Tracker) para o gerenciamento de chamadas técnicas, instalação e configuração de softwares, configuração de clientes de e-mail (gmail, outlook, thunderbird), perfil / acesso, Joomla!3, LimeSurvey e utilização do Sistema Aberto de Eleições Eletrônicas - SAELE. No entanto, nas entrevistas percebeu-se que não existe um planejamento para a manutenção dos computadores e aquisições de peças de reposição.

Para problemas de hardware, observou-se que o primeiro passo consiste em verificar se o computador está na garantia. No caso dos computadores mais antigos a garantia era de 5 anos, enquanto a dos mais novos é de apenas 3. Quando o computador não está mais na garantia, o procedimento inicial consiste em verificar se há peças para reposição oriundas de outros computadores. Caso não haja, um computador novo é fornecido ao usuário e o equipamento defeituoso é descartado no "lixão" da Universidade.

Para os computadores obsoletos, ainda não há um procedimento de diagnóstico implantado. Da mesma forma, também não há nenhum controle das manutenções feitas previamente ao descarte. 
Alguns entrevistados comentaram que se esse diagnóstico fosse feito, além das possibilidades de reaproveitamento dos equipamentos e/ou de suas peças e componentes aumentarem, seria possível incluir a destinação de verbas para manutenção no planejamento do NTI.

Nos procedimentos da gestão de computadores da UFABC não há uma avaliação prévia das necessidades dos usuários que leve em consideração as configurações dos equipamentos. Da forma como vem sendo conduzida, não é possível saber a priori o nível de complexidade da demanda do usuário para orientar objetivamente a substituição. Desta forma, computadores sofisticados, com alto desempenho e placas de vídeo diferenciadas, podem estar sendo alocados para atividades de baixa complexidade como, por exemplo, uso da Internet, edição de textos e preparação de slides, dentre outros.

\subsection{Aquisições de novos computadores}

As aquisições de computadores se dão em grandes lotes e o controle de qualidade é feito via amostragens por lote. A pesquisa revelou que este procedimento não é funcional, pois alguns equipamentos, tidos como "novos", por estarem fora da garantia e/ou não funcionando adequadamente, já são descartados e considerados obsoletos.

Para se minimizar os efeitos desse problema, cabe lembrar que segundo a Lei 8.666/93 de Licitações Públicas (Brasil, 1993) não há impedimentos para fracionar a entrega de grandes lotes, desde que na elaboração do termo de referência, edital e contrato, esteja esclarecido o porquê do fracionamento. Neste caso, a justificativa poderia ser evitar a formação de grandes estoques e a deterioração da qualidade de equipamentos novos. Um importante fator apontado por Tsydenova \& Bengtsson (2011), que fortalece a necessidade de conservação desses equipamentos novos em estoque, é a presença de substâncias perigosas como o chumbo no vidro do cone dos monitores, o bário no canhão de elétrons e o cádmio no pó fosforescente.

A fiscalização também é uma atividade muito importante nas novas aquisições, pois os computadores podem sofrer alterações durante o uso em relação às especificações de contrato. Os entrevistados comentaram que essas alterações precisam ser apontadas no termo de referência para que a Universidade tenha condições de cobrar posteriormente pela garantia de qualidade dos equipamentos adquiridos. Nesse sentido, é importante destacar também a existência da Instrução Normativa $n^{\circ}$ 04/2014 (Brasil, 2014), que orienta a aquisição de material de informática.

No que tange às especificações técnicas para a compra de computadores, verificou-se que a cartilha que orienta as compras verdes sustentáveis para EEEs não foi utilizada em todas as aquisições de computadores pela UFABC. Constatou-se que nas primeiras compras as preocupações se concentravam na estabilidade de energia das fontes e no atendimento de normas da ABNT, sem se ater aos aspectos e impactos ambientais dos equipamentos durante o uso e após o descarte. Já na maioria das licitações de compras efetuadas entre 2010 e 2013 observou-se uma maior preocupação com as questões ambientais, pois certificações obtidas pelas empresas participantes e opção por equipamentos com menor consumo de energia foram itens considerados.

Uma maior preocupação da Universidade em relação ao atendimento de normas, diretivas e instruções de trabalho relativas à reposição de peças e componentes vem sendo observada nos últimos anos. Em licitação de 2011, a Universidade exigiu que a reposição de baterias nos equipamentos de TI por parte de uma empresa contratada fosse feita em consonância com a Resolução Conama 257/99, de 30/06/1999 (Brasil, 1999). Mediante essa orientação, a empresa assumiu a responsabilidade e os custos de descarte de todos os acessórios usados. Da mesma forma, para a aquisição de computadores, de materiais para cabeamento estruturado e de equipamentos de Data Center, o atendimento dos requisitos da Diretiva RoHS (Restriction of Hazardous Substances Directive) se tornaram exigências recentes. O Quadro 1 resume os principais resultados e recomendações da pesquisa. 
Quadro 1: Resultados e recomendações

\begin{tabular}{|c|c|c|}
\hline Assunto & Resultado & Recomendação \\
\hline $\begin{array}{l}\text { Armazenamento dos } \\
\text { computadores obsoletos }\end{array}$ & $\begin{array}{c}\text { Feito em local chamado "lixão" com } \\
\text { poucas ações de recondicionamento } \\
\text { prévio }\end{array}$ & $\begin{array}{l}\text { Criar cultura para reaproveitar os } \\
\text { computadores; criar procedimentos } \\
\text { para manutenção }\end{array}$ \\
\hline $\begin{array}{c}\text { Desfazimento dos } \\
\text { computadores obsoletos }\end{array}$ & $\begin{array}{l}\text { Os computadores obsoletos descartados } \\
\text { no lixão são destinados ao desfazimento } \\
\text { conforme decreto } \mathrm{n}^{\circ} 99.658 / 90\end{array}$ & $\begin{array}{l}\text { Procurar manter o patrimônio na } \\
\text { Universidade via extensão da vida útil } \\
\text { dos equipamentos }\end{array}$ \\
\hline Manutenção dos computadores & $\begin{array}{l}\text { Acionamento da garantia ou trocas de } \\
\text { peças }\end{array}$ & $\begin{array}{c}\text { Comprar peças, estabelecer critérios e } \\
\text { perfis de usuários para os } \\
\text { computadores }\end{array}$ \\
\hline Aquisições de grandes lotes & $\begin{array}{c}\text { Testes por amostragem visando } \\
\text { detecção de computadores novos com } \\
\text { defeito }\end{array}$ & $\begin{array}{c}\text { Declarar no processo de compra que os } \\
\text { computadores serão entregues } \\
\text { conforme demandas }\end{array}$ \\
\hline Licitações dos computadores & $\begin{array}{l}\text { Os requisitos de sustentabilidade nem } \\
\text { sempre foram levados em conta }\end{array}$ & $\begin{array}{l}\text { Explorar a possibilidade de } \\
\text { fracionamento de compras para reduzir } \\
\text { problemas de controle de qualidade }\end{array}$ \\
\hline Fiscalizações de compras & Feita apenas por amostragem & $\begin{array}{c}\text { Exigir melhor qualidade dos } \\
\text { equipamentos }\end{array}$ \\
\hline $\begin{array}{l}\text { Especificações técnicas para } \\
\text { compras sustentáveis }\end{array}$ & $\begin{array}{l}\text { Preocupações iniciais mais focadas na } \\
\text { estabilidade das fontes de energia e no } \\
\text { atendimento de normas da ABNT }\end{array}$ & $\begin{array}{c}\text { Utilizar a cartilha de compras } \\
\text { sustentáveis e a Instrução Normativa n } \\
04 / 2014\end{array}$ \\
\hline $\begin{array}{l}\text { Atendimento de normas, } \\
\text { diretivas e instruções de } \\
\text { trabalho }\end{array}$ & $\begin{array}{l}\text { Atendimento da Resolução Conama } \\
257 / 99 \text { e da Diretiva RoHS }\end{array}$ & $\begin{array}{c}\text { Seguir todas as instruções normativas, } \\
\text { cartilhas, e normas ISO e ITIL para } \\
\text { criar procedimentos e documentação } \\
\text { interna }\end{array}$ \\
\hline
\end{tabular}

Fonte: Compilado pelos autores (2015).

\section{CONCLUSÕES E RECOMENDAÇÕES}

Os resultados dessa pesquisa indicaram que a UFABC ainda não tem procedimentos sistematizados para a gestão dos REEEs visando à otimização da vida útil dos computadores obsoletos. No entanto, além de já ter práticas para o gerenciamento dos computadores novos, informalmente também já vem reaproveitando peças e componentes de alguns equipamentos condenados ao descarte. Espera-se que os resultados desse estudo possam auxiliar a UFABC a reavaliar as suas práticas atuais e subsidiar a implantação de uma política institucional de gestão de TI enfatizando a ampliação da vida útil dos computadores pessoais.

A grande quantidade de computadores obsoletos existente na UFABC atualmente sinaliza para a necessidade de mudanças no atual processo de gestão. Um dos desafios a ser enfrentado será manter o atual parque de TI funcionando adequadamente frente à expectativa de que os usuários tenderão a continuar exigindo equipamentos cada vez mais sofisticados e com desempenhos elevados.

A pesquisa também apontou que os principais fatores que dificultam a gestão dos computadores na Universidade relacionam-se à: (i) falta de interesse dos primeiros gestores no assunto e (ii) falta de disponibilidade de locais adequados para estocagem dos equipamentos e implantação de oficina de manutenção e reparos. Somam-se a isso, questões de ordem burocrática que dificultam decisões e trâmites por parte da Prefeitura Universitária. O entendimento dessas dificuldades de gestão dos computadores na UFABC é consistente com os problemas de gestão das IES apontados por Zhang et al., (2011), quais sejam: (i) ampla burocracia; (ii) falta de integração das áreas internas devido à gestão descentralizada e (iii) pouca clareza de responsabilidades por parte da maioria do pessoal alocado em atividades relacionadas ao assunto.

Tendo em perspectiva que a obsolescência programada deverá continuar encurtando a vida útil dos computadores e que as verbas para novas aquisições deverão ser reduzidas no orçamento da Universidade, vislumbra-se que os desafios impostos aos NTI poderão ter um efeito positivo na adoção de novas práticas de gestão sustentável dos computadores. Neste sentido, presume-se que 
uma mudança cultural entre os colaboradores da UFABC, quanto ao prolongamento do tempo de uso dos computadores, também será necessária. Esta última pressuposição se coaduna com a necessidade da implantação da Agenda Ambiental para a Administração Pública (A3P), mencionada por Barata et al. (2007), cujo objetivo é criar uma cultura institucional na administração pública para a conscientização dos servidores quanto à otimização do uso dos recursos, o combate do desperdício e a busca de melhor qualidade no ambiente de trabalho.

Em contraposição à gestão atual dos computadores da UFABC, sugere-se que os computadores não sejam enviados diretamente para o descarte sem que antes passem por uma avaliação criteriosa e classificação. Este procedimento permitirá a separação de peças para reposição propiciando que os equipamentos classificados como obsoletos não sigam diretamente para o "lixão" da Universidade.

Como sugerido por Barata et al. (2007) para as IES, a UFABC poderá utilizar tanto a Agenda Ambiental da Administração Pública (A3P) como a Norma ISO 14.001 na elaboração dos seus procedimentos de gestão, pois ambas têm pontos em comuns em seus procedimentos. Porém, é importante destacar que a A3P não traz levantamentos dos aspectos, impactos ambientais e planos de emergência, elementos que são considerados na Norma ISO 14.001.

No caso da UFABC vir a implantar um sistema de gestão ambiental baseado na Norma ISO 14.001, o ciclo PDCA (Planejar, Executar, Verificar e Agir), segundo Tauchen \& Brandli (2006), poderá ser um importante referencial para a condução de análises detalhadas dos fluxos de equipamentos e resíduos de TI em seus campi. Isso possibilitará à Universidade considerar questões econômicas e a avaliação de indicadores ambientais neste processo para estimar os potenciais de melhoria.

Para se iniciar a incorporação dos Princípios dos 3Rs nas atuais práticas de gestão de computadores da Universidade, recomenda-se que as compras sejam reduzidas para o nível das reais necessidades, reaproveitando os equipamentos usados conforme um diagnóstico de situação e orientações baseadas em perfil de usuário alinhado à configuração de cada máquina. Isso propiciaria o descarte somente dos computadores que não têm chances efetivas de aproveitamento. Apoiandose na afirmação de Bizzo (2007) de que mais de $90 \%$ dos materiais que compõem um computador podem ser recuperados, a incorporação dos 3Rs na gestão de TI da UFABC contribuirá para reduzir a quantidade atual de equipamentos obsoletos (estimada em 500) e, consequentemente, reduzir o uso de matérias-primas e insumos (metais, petróleo, água, energia) utilizados no processo produtivo, como é sugerido por Samiha (2013) e Nordin et al. (2015). Além disso, propiciará a circulação dos materiais contidos nesses equipamentos por mais tempo na cadeia produtiva.

Outra recomendação é incentivar a rotatividade de computadores, ou seja, a destinação de um equipamento com menos recursos para os usuários cujas atividades exijam apenas configuração mais simples, como recomendado por Peters (2009) de modo a otimizar a sua alocação. E também temos Zhang et al. (2011) que estimulam a adoção de práticas de reutilização e reciclagem. Pois Novaes \& Zanta (2011) criticam o elevado consumo e descarte precoce desses equipamentos ainda em plenas condições de funcionamento, já no final de suas "primeiras vidas", bem justificado por Tsydenova \& Bengtsson (2011) e Nordin et al. (2015) pois os computadores possuem substâncias nocivas ao meio ambiente.

Algumas práticas adicionais que poderão integrar uma política de TI para a UFABC são as seguintes:

i) A elaboração de um guia de boas práticas para dar suporte à gestão dos computadores obsoletos contendo instruções de trabalho, normas do setor e as políticas de destinação dos equipamentos em desuso, e opções de destinação final baseadas em parâmetros como tipo / modelo dos equipamentos, e recursos nele contidos, uma recomendação é o fluxo de opções para EEEs de Manthou et al. (2013);

ii) A criação de uma Instrução de Trabalho (IT) para cada uma das quatro atividades: diagnóstico do computador; diagnóstico do monitor, geração de relatório de situação; e 
acondicionamento do monitor; a IT atual engloba conjuntamente essas quatro atividades tornando-a pouco objetiva e eficiente;

iii) A criação de uma Instrução de Trabalho (IT) para diagnóstico de peças, acondicionamento do CPU (computer processing unit ou computador completo sem monitor), acondicionamento de peças, acondicionamento de resíduos, boas práticas para manutenção de hardware e também do colaborador, incluindo limpeza e atualizações;

iv) A adoção da Norma ISO 20.000 como padrão de referência de melhores práticas para serviços de TI pelo fato dela ser compatível com o Information Technology Infrastructure Library (ITIL), que trata do gerenciamento de serviços nessa área (Norma ISO/IEC 20000, International Organization for Standardization, 2005);

v) A realização de compras de computadores e outros equipamentos com certificado "verde", fabricados a partir de materiais recicláveis e versáteis em termos de reutilização e desmonte em consonância como sugerido por Babbitt et al. (2011);

vi) $\mathrm{O}$ encaminhamento para leilões públicos é uma prática comum, que também ocorre no Griffith College (Davis \& Wolsky, 2009) e na UFRGS (Natume et al., 2011; Menezes, 2014; Neutzling et al., 2014), mas cabe priorizar somente equipamentos com potencial de reuso, de modo a ampliar suas vidas úteis e

vii) Alterações no Plano Diretor de TI da Universidade de modo a contemplar verbas para aquisição de peças de reposição para manutenção dos computadores e acessórios.

Há também a opção de acionar empresas fabricantes de computadores para efetuarem a recolha dos REEE apontado por Nordin et al. (2015).

Por fim, como o presente estudo contemplou entrevistas com apenas 9 colaboradores, essa limitação da pesquisa sugere que uma investigação similar seja submetida a uma amostra maior e mais diversificada de colaboradores para consubstanciar melhor os resultados obtidos tendo em vista subsidiar uma política de TI para a UFABC. Sugere-se também que outros públicos, como mais membros da alta direção da Universidade e os usuários dos equipamentos também sejam entrevistados para ampliar e robustecer as recomendações aqui apresentadas.

\section{REFERÊNCIAS}

Aligleri, L., Aligleri, L. A., \& Kruglianskas, I. (2009). Gestão Socioambiental: Responsabilidade e Sustentabilidade do Negócio. São Paulo: Atlas.

Associação Brasileira de Normas Técnicas (2004). Norma Brasileira ISO 14001: Sistemas de gestão ambiental - requisitos com orientação para o uso. Rio de Janeiro: Autor.

Associação Brasileira de Normas Técnicas (2004). Norma Brasileira 10.004 - Resíduos Sólidos Classificação. Rio de Janeiro: Autor.

Babbitt, C. W., Williams, E., Kahhat, R. (2011). Institutional disposition and management of endof-life electronics. Environ Science \& Technology, (45), 5366-5372.

Barata, M. M. L., Kligerman, D. C., \& Gomez, C. M. (2007). A gestão ambiental no setor público: uma questão de relevância social e econômica. Revista Ciência \& Saúde Coletiva, 12(1), 165-170.

Bizzo, W. A. (2007). Gestão de resíduos e gestão ambiental da indústria eletro-eletrônica. Campinas: Unicamp / Faculdade de Engenharia Mecânica.

Brasil. (1990). Decreto n. 99.658/1990. Regulamenta o reaproveitamento, a movimentação, a alienação e outras formas de desfazimento de material. Recuperado em 6 de fevereiro de 2014, de http://www.planalto.gov.br/ccivil_03/decreto/antigos/D99658.htm

Brasil (1993). Lei $n^{o}$ 8.666, de 21 de junho de 1993. Recuperado em 15 de fevereiro de 2014 de http://www.mma.gov.br/port/conama/res/res99/res25799.html 
Brasil (1999). Resolução Conama $n^{o}$ 257, de 30 de junho de 1999. Ministério do Meio Ambiente. Recuperado em 15 de fevereiro de 2014, de http://www.mma.gov.br/port/conama/res/res99/res25799.html.

Brasil. (2014). Instrução Normativa $n^{o} 04$ Recuperado em 6 de fevereiro de 2014, de http://www.governoeletronico.gov.br/sisp-conteudo/nucleo-de-contratacoes-de-ti/modelo-decontratacoes-normativos-e-documentos-de-referencia/instrucao-normativa-mp-slti-no04

Brasil. (2010). Lei 12.305 - Política Nacional de Resíduos Sólidos - PNRS. Ministério do Meio Ambiente. Recuperado em 6 de julho de 2014, de http://www.mma.gov.br

Bueno, A. P., Haumann, C. F., \& Schmidt, P. A. C. (2013). Levantamento de dados sobre a reciclagem do lixo eletrônico no município de Medianeira-PR. Tecno-lógica-Revista do Depto. de Química e Física, do depto. de Engenharia, Arquitetura e Ciência Agrárias e do Mestrado em Tecnologia Ambiental, 17(1), 52-59.

Carvalho, S. R. C. (2013). A Sociedade de risco e o descarte de computadores. Revista Eletrônica do Curso de Direito-UFSM, 264-275.

Choi, B. C., Shin, H. S., Lee, S. Y., \& Hur, T. (2006). Life Cycle Assessment of a Personal Computer and its Effective Recycling Rate. Int J LCA, (11), 122 - 128.

Comissão Mundial sobre Meio Ambiente e Desenvolvimento (1987). Nosso futuro comum. Rio de Janeiro: Fundação Getúlio Vargas.

Comunidade Europeia. (2002). Diretiva Europeia 2002/95/CE (RoHS) Restrição do uso de determinadas substâncias perigosas em equipamentos elétricos e eletrônicos. Parlamento Europeu e Conselho. Jan./2003. Recuperado em 1 julho de 2013, de http://eurlex.europa.eu/LexUriServ/LexUriServ.do?uri=CELEX:32002L0095:PT:HTML

Creswell, J. W. (2007). Qualitative inquiry and research design: choosing among five approaches. (2nd ed.). Thousand Oaks, CA: SAGE Publications.

Davis, G., Wolski, M. (2009). E-waste and the sustainable organization: Griffith University's approach to e-waste. Emerald International Journal of Sustainability in Higher Education, 10(1), 21-32.

Elkington, J. (2001). Canibais com garfo e faca. (P. M. Ramalho, trad.. L. S. Maia, rev. Técnica). São Paulo: Makron.

Esposito, E., Mastroianni, M. (2002). Information technology and personal computers: the relational life cycle. Technovation, (22), 41-50.

Fundação Getúlio Vargas. (2013). 24ª Pesquisa Anual de Uso de Tecnologias da Informação. São Paulo: Autor. Recuperado em 1 outubro de 2013, de http://eaesp.fgvsp.br/sites/eaesp.fgvsp.br/files/arquivos/gvpesqti2013ppt.pdf

Gao, L., Xia, K., Jin, G. Q., Chao, K-M, Li, W. D. (2012). Sustainable information management for waste electrical and electronic equipment. In IEEE $16^{\text {th }}$ International Conference on Computer Supported Cooperative Work in Design.

García, G. A., Moguel, R. G., Cabrera, M. L., \& Acevedo, J. (2012). Policy options for the management of end of life computers in Mexico. Clean Techn Environ Policy, 14, 657-667.

International Organization for Standardization. (2005). Norma ISO/IEC 20000 - Information technology-Service management-Part 1: Specification. Genève, Suíça. Recuperado em 1 julho de 2014, de http://webstore.iec.ch/p-preview/info_isoiec20000-1\%7Bed1.0\%7Den.pdf

Kahhat, R., \& Williams, E. (2009). Product or Waste? Importation and End-of-Life Processing of Computers in Peru. Environ. Sci. Technol, (43), 6010-6016. 
Kunal, S., Anwesha, B. (2013). Eletronic waste management in India: A stakeholder's perspective. Electronic Green Journal, 1(36).

Lima Jr., F.R., \& Oiko, O. T. (2009). Gestão de Resíduos de equipamentos eletro-eletrônicos: um estudo de caso sobre a caracterização e destinação na UEM. In Encontro Nacional de Engenharia de Produção. Rio de Janeiro: ABEPRO.

Manthou, V., Emmanouil, M. C., Stiakakis, E., Vlachopoulou. (2013). An analysis of waste and information flows in an ICT waste management system. Procedia Technology, (8), 157-164.

Martins, G. A., \& Theóphilo, C. R. (2009). Metodologia da investigação científica para ciências sociais aplicadas. (2a ed.) São Paulo: Atlas.

Menezes, C. M. V. M. C. (2014). Gestão de resíduos sólidos em Instituições de Ensino Superior: o programa USP Recicla no campus de São Carlos. Dissertação de Mestrado, Universidade Nove de Julho, São Paulo.

Ministério do Meio Ambiente. (2014). Agenda Ambiental na Administração Pública (A3P). Recuperado em 1 fevereiro de 2014, de http://www.mma.gov.br/responsabilidadesocioambiental/a3p/item/8852

Natume, R. Y., Oréfice, E. H., Trentini, A. B., Oliveira, T. V. (2011). Gerenciamento de resíduos de informática nas universidades federais do Brasil. In 11 Colóquio Internacional Sobre Gestão Universitária na América do Sul. Florianópolis.

Neutzling, D. M., Nascimento, L. F. M., Santos, C. A. F. (2014). A gestão dos resíduos de equipamentos eletroeletrônicos (REEE) e as consequências para a sustentabilidade: As práticas de descarte dos usuários organizacionais. Revista Capital Científico - Eletrônica (RCCe), 12 (1), Janeiro/Março.

Nordin, N. A. M., Kasapo, P., Agamuthu. (2015). E-waste flow among selected institutions of higher learning using material flow analysis model. Resources, Conservation and Recycling, (105), 177-185.

Novaes, M. P., Zanta, V. M. (2011).O reuso de computadores pós-consumo: desafios e oportunidades. In 31 Encontro Nacional de Engenharia de Produção. Belo Horizonte.

Peters, C. (2009). Aumentando o tempo de vida útil de seu computador. Recuperado em em 1 julho de 2014, de https://www.techsoupbrasil.org.br/node/2256

Rahman, S., \& Subramanian, N. (2012). Factors for implementing end-of-life computer recycling operations in reverse supply chains. Int. J. Production Economics, (140), 239-248.

Ravi, V. (2012). Evaluating overall quality of recycling of e-waste from end-of-life computers. Journal of Cleaner Production, (20), 145-151.

Samiha, B. (2013). The Importance of the 3R Principle of Municipal Solid Waste Management for Achieving Sustainable Development. Mediterranean Journal of Social Sciences, 4(3).

Santos, D. T., Dias, G. M., Santos, R. P. A., Silva, U. B., \& Paula, V. V. (2014). Estratégias de gestão no destino do lixo tecnológico: um caso de implantação de um ecoponto na UNIGRANRIO. Blucher Marine Engineering Proceedings, 1(1).

Santos, F. E., \& Souza, S. T. M. (2009). Um estudo das motivações para implantação de programas de logística reversa de microcomputadores. RECADM-Revista Eletrônica de Ciência Administrativa, 8(2), 137-150. 
Schons, C. P. (2012). O gerenciamento dos resíduos eletroeletrônicos: um estudo sobre as empresas de informática em São Miguel do Oeste-SC. E-Tech: Tecnologias para Compettvidade Industrial, Florianópolis, 5(1), 56-88.

Silva, J. R. N. (2010). Lixo eletrônico: um estudo de responsabilidade ambiental no contexto do instituto de educação ciência e tecnologia do Amazonas - IFAM campus Manaus Centro. In Congresso Brasileiro de Gestão Ambiental. Bauru.

Tauchen, J. \& Brandli, L. L. (2006). A gestão ambiental em Instituições de Ensino Superior; modelo para implantação em campus universitário. Gestão \& Produção. set./dez., 13(3), p.503-515.

Teehan, P., \& Kandlikar, M. (2012). Sources of Variation in Life Cycle Assessments of Desktop Computers. Journal of Industrial Ecology, 16(1).

Tsydenova, O., \& Bengtsson, M. (2011). Chemical hazards associated with treatment of waste electrical and electronic equipament . Waste Management, 31(1), p.45-58.

Veit, M. H. (2010). Instituto Humanitas Unisinos - IHU, da Universidade do Vale do Rio dos Sinos - Unisinos. In EcoDebate Cidadania \& Meio Ambiente. São Leopoldo.

Velazquez, L., Munguia, N., Platt, A., \& Taddei, J. (2006). Sustainable university: what can be the matter? Journal of Cleaner Production, 14(9-11), 810-819.

Xavier, L. H., Lucena, L. C., Costa, M. D., Xavier, V. A., \& Cardoso, R. S. (2010). Gestão de resíduos eletroeletrônicos: mapeamento da logística reversa de computadores e componentes no Brasil. In 3 Simposio Iberoamericano de Ingeniería de Residuos.

Yin, R. K. (2005). Estudo de caso: planejamento e métodos. (3ª Ed.). Porto Alegre: Bookman.

Zhang, N., Williams, I.D., Kemp, S., \& Smith, N. F. (2011). Greening academia: Developing sustainable waste management at Higher Education Institutions. Waste Management, (31), 16061616.

Wong, M. H., Kiddee, P., Naidu, R. (2013). Electronic waste management approaches: An overview. Waste Management, (33), 1237-1250.

Wu, H. C. (2012). Price and service competition between new and remanufactured products in a two-echelon supply chain. Int. J. Production Economics, (140) 496-507.

Recebido em: 22/05/2015

Publicado em: 21/12/2015

Revista de Gestão Social e Ambiental - RGSA, São Paulo, v. 9, n. 3, p. 80-96, set./dez., 2015. 